induced often by somo great stbrerstre chatrge in the copditions of climate, food, or clothing, to whicti an individual is subjected

It is contrary to wli our aefinitions, all our rabs of scrofulouts disease, that a man shoutld reach eighty jeats of age, and then manifest scrofula for the first time-a circumstance which tiust be allowed, if nowly developed tubercle has been found at this pexiod of life, as has been esserted, and if' tubercle and scrofula be different manifestation's of one and the samo cachexia.

But my text was the nature and affinities of tabercle, and it is within these limits that $I$ must restrict myself. It has beefi my object to show that tubercle is a new growth; that its nature, tode of development, clinical history, and method of metastasis (an this was discussed at much greater length in the recture as originally delivered), appoint it to a position between eancer and the strictly. lymphomatous tumours.

I would have it further remembered, that no pathological new formations can be regarded as parasitic; that nothing akin to the body is ever grafted on to if that there exist no such things as cells pathognomonic of cancer or of tubercle; that new growths are buit upon normal physiological types; that the structure nearest to tubercle (there is nore exactly like it) is a lymph.gland.

Fastly, as I have endeavoured to show, the diseases of lymph-glands may be classed together as a family having certain features in cónmon, and each and all of them sóme affinity, although really onty a very distant relationship to tubercle. When grouped together about this, as they, have' been, with singular talent and profound knowledge, by Professor Virchow, wa learn that the heterologous mode of its development separates this new growth from them, and alfies it more closely in nature with cancerous tumour.

\section{ON THE REPORT OF THE VENEREAL COMMISSION.}

\author{
BY HOLMES COOTE, EsQ., F.R.C.S., \\ surgeon to st. Bartbolomet'd Hơsptal.
}

TFE Report of the Cammittee appointed by the Tords of the Admiralty to inquire into the best mode of treatment of the venereal disease, has at least had the good effect of olearing the sutbject of much that was ambiguous, theoretical, or irielevant, and has laft it open to zot further inquiry. $A$ syphulitio virus is recognised; the disease is protonticed as specific as small-pox. But here the resemblance must cease: there is no further athalogy between the two diseases a and I trust rever again to see repeated those cruel experiments by which it was attempted to render the body insusceptible to the further action of the virus by repeated inoculations.

The weight of exidence went to prove that syphilis, under favouring circumstances, might be generated spoptaneously. And perinit me to ásk, as regards this point, in what respect the history of syphilis differs from that of any other known disease? Do we know the origin of small pox, of measles, or of scarlatina? Can we explain the nature of the cholera paison? To say that syphilis may possibly have been derived from the horse, is a purely fanciful statement, which is unworthy of any scientific tork.

It being, then, established, first, that there is such a disease; and secondly, that there is a specific virus, - the Committee next proceeds to the sutbject of primary sores; and here, in my opinion, is the first break-down.

Two species of sores are described; namely, first, the I: simple loctl sores the influende of which never extends beyond the inguinal glands, but is eminently contrigious; though ancaparle of infecting the constitution. This is the most common, and prevails over all other varieties in a ratio of about 4 to 1 :" secondly, the syphilitic, sore, which, according to this Report, is not always indurated, as was the prevailing opinion some weeks, ago, but which may be indurated throughout its entire course; or soft in its early stage, and subsequently indurated or soft. throughout its entire course, but which, unlike the simple local sore, is followed by constitutional disease. The evidence, further, is conclusive that it is impossible to pronounce with certainty on the characters of a sore on its first appearance.

Now I mainfain that such conelusions as these are useless to us in a modical point of view, and may become mischievous to our patients. The theories about "znduration" as characteristic of syphilis are gone. The soft syphilitic sore cannot be distin. guished from the soft non-syphilitic sore, except by its progress and history. If, according to the Report, a rash come over the body, it is syphilitic if not so, it is a simple sore But the surgeon who honestly entertains this belief, can only reply to his patient's anxious inquiries respecting the character of the disease, "I cannot tell you its nature until it has come to an end. If you suffer from constitutional symptoms, it is syphilitic; if not, it is non-syphilitic." The patient might reply, that he could have told the surgeon as much himself.

Such arguments ramind me of those once entertained respecting the use of mercury. If the sore is cured by mercury, it is syphilitic; if not so, It is non-syphilitic.

But these arguments may become mischiexous. Is there a sane surgeon living who, if his life de pended on it, would undertake to guarantê to a patient the sabject of any form of venereal sore Whatever, that he should be free from the occurrence of constitutional infection? Should there be any one who really attaches importance to the mattar of or induration, I could speedily produce eviatetce to bring him to very different opinion. That some persons suffer constitutionally, and some do not, is a matter of general notoriety, but surtely all individuals are not equally sưceptible of general syphi-

According to this Report, the frequency of ennstitutional symptoms to primary sores of all kifids should be four to one. Taking the female venereal cases which are in constant succession under my care, I stould pronounce the number at least onehalf and then, many who quit the hospital apparently well, and not generally infected, suffer from secondary symptomis deterwatds. So also, amotig the men, secondary symptomis are common ; but the induration of the base of the primaiy sofe is of rare occurrence, and is scarcely ever seen in wonden.

I see no reason to chinge my opinion from that which has been already published and expressed; thamely; that there is but one venereal virus, the action of which' is ustally chronic, and always ulcerative. The character of the sore thus produced tepends, in any other case, on the nature of the tissue on which it acts; and, caterls paribus, the same tissue presents the same kina of venereal ulcers. These ulcers are not precisely similar in the male and female; nor in the former are they always the same, inasmuch as they vary in character just as often as the tisques, composing the penis vary in

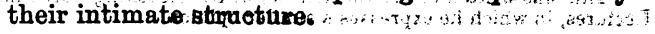

